\title{
Resistance to extinction of a learned taste aversion varies with time of conditioning
}

\author{
JOSEPH W. TERNES \\ Caribbean Primate Research Center, University of Puerto Rico Medical School, \\ Sabana Seca, Puerto Rico
}

\begin{abstract}
Sixteen rats were maintained out of doors in cages with natural light, temperature, and social stimulation for 3 months. Subsequently, by pairing the taste of sucrose with IP injections of LiCl, the rats were conditioned to avoid sucrose. Each of four groups of rats received the CS-US pairing at a different time of day. Times of conditioning were 6 a.m., 12 a.m., 6 p.m. and 12 p.m. EST. A twobottle preference test between $4 \%$ sucrose solution and tap water was initiated $24-\mathrm{h}$ after conditioning. Daily measurements of preference were continued for 16 consecutive days. Results indicated that, although all groups initially exhibited equivalent sucrose aversions, the groups conditioned at 12 a.m. and 6 p.m. extinguished within 12 days while the 6 a.m. and 12 p.m. groups continued to manifest profound aversions for sucrose throughout the 16 test days.
\end{abstract}

Several factors affect the response strength of conditioned taste aversions. Prior exposure to either the CS (Ahlers \& Best, 1971; Domjan, 1972; Revusky \& Bedarf, 1968; Vogel \& Clody, 1972) or the US (Berman \& Cannon, 1974; Brookshire \& Brackbill, 1972; Elkins, 1974) is known to impair and in some instances completely block conditioning. Parameters such as the paradigm (US preceding CS or CS preceding US), the interstimulus interval (Barker \& Smith, 1974; Barker, Suarez, \& Gray, 1974), and the amount of CS consumed (Barker, 1976; Bond \& Di Giusto, 1975; Bond \& Harland, 1975) have differential effects on the strength of a flavor aversion.

US intensity also affects response strength. Garcia, Kimeldorf, and Koelling (1955) reported that the strength of a conditioned taste aversion, measured by both the degree of the initial aversion as well as resistance to extinction, was dose dependent when radiation was employed as the US. Smith and Morris (Note 1) found that while the rate of irradiation did not affect the degree of initial aversion, its strength was directly related to the total cumulative dose. Nachman and Ashe (1973) found a monotonic relationship between the dose of lithium chloride ( $\mathrm{LiCl}$ ) injected on a single trial and the strength of the learned taste aversion. The concentration, volume, and route of administration did not significantly affect the degree of conditioning. Garcia, Ervin, and Koelling (1967) varied dose magnitudes of cyclophosphamide and reported an orderly relationship between aversion acquisition and dose parameters. Elkins (1973) also used cyclophosphamide as an US and found long-lasting saccharin aversions which were dose-dependent relative to both

The author's present address: Joseph W. Ternes, Monell Chemical Senses Center, University of Pennsylvania, 3500 Market Street, Philadelphia, Pennsylvania 19104. initial magnitude and resistance to extinction. He also found differential dose-related resistance to extinction in groups which initially displayed equivalent aversions. He suggested that under parameters which produce strong initial aversions, resistance to extinction may be the most appropriate test of differential aversion strength. Thus, within a particular stimulus dimension, US intensity is considered to be directly related to associability such that certain low values are thought to be either insufficient or minimally effective while higher values are thought to reliably produce the phenomenon.

Seldom has there been any consideration of differential receptivity or suceptibility of the organism which could modulate the effectiveness of an US and affect response strength. However, reports of cycling susceptibility to pneumonococcus (Feign, San Joaquin, Haymond, \& Wyatt, 1969), to barbiturates (Scheving, Ledral, \& Pauley, 1968), to amphetamine (Scheving, 1968), and to radiation (Haus, Halberg, Locken, \& Kim, 1974; Pizzarello, Isaak, \& Chua, 1963) would suggest the existence of circadian susceptibility rhythms. These rhythms may influence the learning of flavor aversions, since toxins, drugs of abuse, and radiation are commonly used as USs. Ternes and Smith (Note 2) reported results of a series of experiments in which seven groups of rats were adapted to a cycling 12-12 light-dark illumination schedule and then irradiated with $\mathrm{CO}^{60}$ immediately after drinking saccharin. The dose, $50 \mathrm{R}$, was the same in all groups. The independent variable was the time of day when the different groups were exposed to irradiation. The results suggested that a single dose of radiation was differentially effective in producing conditioned saccharin aversion as a function of the time of exposure. The groups were also differentially resistant to extinction. The authors suggested that 
a circadian rhythm of suceptibility to radiationinduced taste aversion had been demonstrated. Ternes (1974) compared two doses of $\mathrm{CO}^{60}, 60$ and $30 \mathrm{R}$, for circadian dose interactions. Rats were synchronized to a 12-12 light-dark cycle, and three separate groups were irradiated at different times, each separated by $8 \mathrm{~h}$, within a $24-\mathrm{h}$ period. The results indicated that both dose and time of conditioning were significant factors affecting the strength of the initial aversion. Although this study found differential US effectiveness, it cannot be considered as a replication of the findings of Ternes and Smith (Note 2), since the specific phases of highest sensitivity to radiation (times when the strongest aversions were produced) differed considerably between the two studies. Ternes and Smith (Note 2) found that profound aversions were conditioned toward the end of the dark period, while Ternes (1974) found the strongest aversions were conditioned toward the end of the light period. Recently, Etscorn and Miller (1975) found variations in the strength of a conditioned aversion using cyclophosphamide as the US. Although they expected to obtain better conditioning during the dark phase of the circadian rhythm, their results showed that significantly greater aversions were produced toward the end of the light phase. Fortuitously, their study was similar to Ternes (1974) in that they used young rats as subjects and adapted their animals for 2 weeks prior to conditioning. Both studies found that the phase $3 \mathrm{~h}$ prior to light of fset yielded the strongest aversions.

Rusak and Zucker (1974) have reported differential strengths of conditioning of saccharin aversions as a function of maintenance lighting conditions. They suggest that a circadian rhythm of susceptibility of $\mathrm{LiCl}$ would account for their results. The present experiment was performed to test this hypothesis, and to clarify the discrepancies between Ternes (1974) and Ternes and Smith (Note 2) relative to the times when rats are most sensitive to taste aversion conditioning.

\section{METHOD}

\section{Subjects}

Subjects were 16 Wistar-strain male rats, approximately 2 years old at the start of the experiment. They were housed in standard Holtge wire cages in an open-air animal shelter at the Caribbean Primate Research Center, Sabana Seca, Puerto Rico. Although the enclosure provided cover from direct sun and rain, there were no walls, as such. Thus, they experienced the natural light and temperature cycles prevailing in Sabana Seca during February, March, and April 1974. Temperatures ranged from $22^{\circ}$ to $32^{\circ} \mathrm{C}$, with an average low of $24^{\circ}$ and a high of $28^{\circ}$. Sunrise occurred at approximately 6:30 a.m. and sunset at approximately 6:30 p.m. The rats were maintained with ad lib Wayne monkey chow and tap water for 3 months prior to the start of the experiment.

\section{Procedure}

Prior to conditioning, the subjects were randomly assigned to four groups of four rats each. They were not deprived or handled in any way pror to conditioning. On the first day of the experiment, the water bottle was removed from a rat's cage and replaced with a $4 \%$ sucrose solution for $15 \mathrm{~min}$. All animals were observed to sample the sweet solution during this period. Immediately following this conditioned stimulus (CS) presentation perıd, the subjects were injected intraperitoneally with a $15 \mathrm{M}$ solution of $\mathrm{LiCl}$ equivalent to $2 \%$ of body weight. The time of conditioning (presentation of the $\mathrm{CS}$ followed by $\mathrm{LiCl}$ injection) differed for each group. The times of conditioning were $6 \mathrm{a} . \mathrm{m}$., 12 a.m., 6 p.m., and 12 p.m. Immediately following the injection of $\mathrm{LiCl}$, the rats were deprived of food and water for $24 \mathrm{~h}$. At the end of this deprivation period, they were provided ad-lib food and a two-bottle preference test between $4 \%$ sucrose solution and tap water was initiated. Measurement of sucrose and water consumption was accomplished by weighing the bottles every day. Daily reversal of bottle positions controlled for position preferences. The postconditioning preference test was continued for 16 consecutive days. Subjects' individual preference for sucrose was determined by calculating the percent of the total liquid consumed (water + sucrose) that was in the form of sucrose solution.

\section{RESULTS}

The results of this experiment indicate that differential degrees of aversion were conditioned as a function of the time of the CS-US pairing. Although initially the $\mathrm{LiCl}$ injections produced similar aversions to sucrose in all groups, continued preference testing indicated differential resistance to extinction among the groups.

Figure 1 shows the group mean sucrose preference scores plotted as a function of successive extinction test periods. Rats conditioned at 12 a.m. and 6 p.m. showed less resistance to extinction than rats conditioned at $12 \mathrm{p} . \mathrm{m}$. and $6 \mathrm{a} . \mathrm{m}$. Recovery of sucrose preference was complete within 12 days in the former groups (less resistance to extinction), whereas little, if any, recovery (greater resistance to extinction) occurred in the latter groups during the entire 16 days of preference testing. Thus, the dose-response

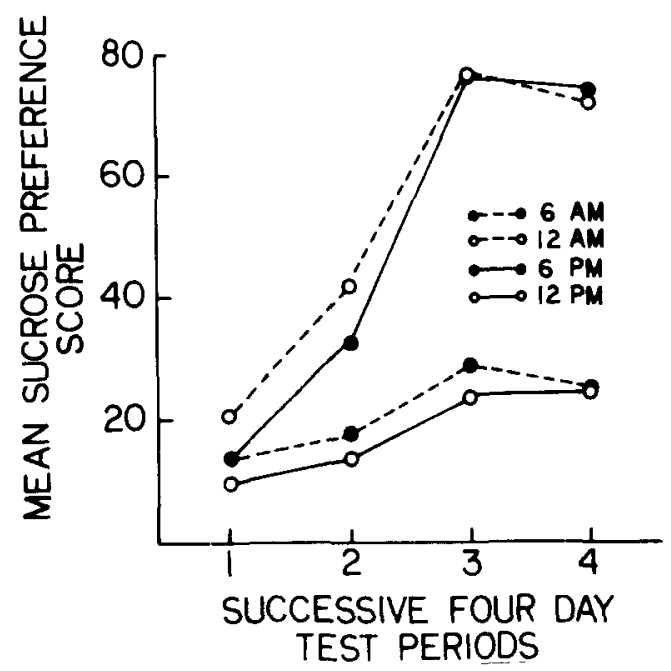

Figure 1. Average sucrose preference scores for four groups as a function of successive extinction test periods. Groups were defined by the time that the CS-US pairing was given. 
relationship was modulated by the time of conditioning.

Preference test data for the 16 days postconditioning was combined into four test periods of 4 days each for purposes of analysis. A 4 (time of conditioning) by 4 (test period) analysis of variance with repeated measures on the second factor, mixed design (Keppel, 1973), was performed on the preference test data. Time of Conditioning $(F=6.45$, df $=3 / 12, \quad \mathrm{p}<.008)$, Test Period $(\mathrm{F}=17.13$, $\mathrm{df}=9 / 36, \mathrm{p}<.001$ ), and the Time of Conditioning by Test Period Interaction $(F=2.09, \mathrm{df}=9 / 36$, $\mathrm{p}<.05$ ) were significant.

The significant interaction prompted tests of simple main effects in each of the four test periods. Time of Conditioning was not significant in the first extinction test period $(p>.5)$; however, it was significant in each of the three succeeding extinction test periods $(p<.05,<.01,<.001$, respectively). Duncan's multiple range test (Keppel, 1973) indicated that there were no significant differences between the means of the $6 \mathrm{a.m}$. and the 12 p.m. groups in Test Periods 2, 3, and 4. Nor were there significant differences between the means of the 6 p.m. and 12 a.m. groups in these same three periods. However, the means of the 6 a.m. and 12 p.m. groups did differ significantly from the means of the $6 \mathrm{p.m}$. and 12 a.m. groups in each of the last three test periods.

Analysis of CS consumption data indicated that differential amounts of sucrose were consumed by the four groups during their respective CS presentation periods. Unexpectedly, a greater hesitancy to drink the novel sucrose solution was demonstrated by rats presented with the CS during periods normally correlated with higher food intake, i.e., during the dark phase of the LD cycle.

Table 1 shows the sucrose consumption of animals in the four groups during the CS presentation period. Mann-Whitney $U$ tests indicated that the 6 a.m. group drank significantly less sucrose during the CS presentation period than the other three groups $(\mathrm{p}<.01,<.02,<.02$, respectively) and the $12 \mathrm{p.m}$. group drank significantly less than the 12 a.m. group $(p<.05)$. No other comparisons were significant.

\section{DISCUSSION}

The CS in this experiment, $4 \%$ sucrose solution, has been used in a number of taste aversion studies but never with such profound and long-lasting effects (e.g., Smith \& Birkle, 1966). However, in the present experiment, special care was taken to insure that the rats' endogenous rhythms were synchronized to the environmental zeitgebers such as light, temperature, and social stimuli by maintaining the animals out of doors for 3 months prior to conditioning. Additionally, these animals received no handling, diet variation, or deprivation of food or
Table 1

M1 Sucrose Consumed During CS Presentation

\begin{tabular}{cccc}
\hline 6 am Group & 12 am Group & 6 pm Group & 12 pm Group \\
\hline 4 & 13 & 5 & 4 \\
3 & 11 & 14 & 6 \\
3 & 16 & 10 & 13 \\
6 & 10 & 6 & 7 \\
\hline
\end{tabular}

Note-Each entry represents an individual rat's consumption.

fluid which might otherwise have desynchronized some of the component circadian rhythms. Hence, these results provide a norm for the evaluation of sucrose aversions learned in states of depletion and rhythm desynchrony.

The present experiment showed that the rats' normal activity period is a propitious time for learning. Ternes and Smith (Note 2) also found stronger aversions to saccharin in groups conditioned toward the end of the dark (rats' activity period) phase. These results are at variance with those of Etscorn and Miller (1975) and Terres (1974), who found that the best conditioning occurred $3 \mathrm{~h}$ before dark. Procedural differences such as the length of habituation of the animals prior to conditioning, age, and strain of the subjects, and the type of US probably account for these conflicting results. The present study used 2-year-old rats, and Ternes and Smith (Note 2) used old breeders which were 2 to 3-years-old. However, Ternes (1974) used young (70to 80-day-old) rats, as did Etscorn and Miller (1975), whose rats were 100 to $105 \mathrm{~g}$. Likewise, the present study habituated the rats to the test environment for 3 months prior to conditioning and Ternes and Smith (Note 2) also habituated their animals for at least 2 months prior to conditioning. On the other hand, Ternes (1974) and Etscorn \& Miller (1975) both habituated their subjects for only 2 weeks. Thus, although the phenomenon itself is well established, systematic investigation of the parameters of the circadian sensitivity effect remains to be done. However, this demonstration suggests that care should be taken to report the maintenance lighting conditions, habituation parameters, and the time of training in taste aversion conditioning studies.

One explanation for the present results is that circadian cyclic variations in organismic sensitivity to the US could result in differential taste aversion learning. This interpretation is supported by reports of changing resistance to illness (Feign et al., 1969), to drugs (Scheving, 1968; Scheving et al., 1968), and to ionizing radiation (Pizzarello et al., 1963; Haus et al., 1974).

However, an alternative explanation might also be considered. The associability of the CS with poison could vary as a function of time of conditioning. The cyclical nature of feeding and drinking in the rat has frequently been reported (e.g., Siegel, 1961; Siegel \& Stuckey, 1947). Laboratory rats 
typically drink $85 \%$ of their daily water intake during the dark portion of a diurnal cycle (Rusak \& Zucker, 1974). It would, therefore, be reasonable to assume that rats presented with a novel sapid solution would ingest more if it was presented during the dark phase of the feeding cycle. Thus, it was predicted that nondeprived rats would imbibe more $4 \%$ sucrose solution and learn more profound aversions during this period. The results are paradoxical in that groups conditioned at night showed more profound aversions but drank less of the CS than the groups conditioned during the day. Hence, the rats were more suspicious of the sucrose solution at night than during the day.

Recent evidence (Kalat \& Rozin, 1973; Nachman \& Jones, 1974; Revusky \& Bedarf, 1967) has shown that rats learn stronger aversions to solutions which evoke a neophobic response. Carroll, Dinc, Levy, and Smith (1975) have suggested that the degree of neophobia resulting from the initial presentation of a taste solution might be a good predictor of the strength of a learned aversion subsequently conditioned to the same solution. In the present study, the 15-min CS presentation was the first exposure these rats had to sucrose. Their consumption of differential amounts of the CS might be considered cyclic neophobia which varied as a function of the time of presentation. Best (1975) has distinguished between latent inhibition and conditioned inhibition in taste aversion learning by pointing out that conditioned inhibition can only occur within a mildly aversive excitatory context. Neophobia would provide such a context but, if it is cyclic, only at certain times of day. If one assumes that an excitatory context facilitates learning, either of safety or of danger, then differential conditioning should result as a function of cyclic neophobia to the CS. Such a hypothesis would predict either a rhythm of suceptibility to taste aversion conditioning or a similar rhythm of susceptibility to conditioned inhibition, depending on procedures used.

\section{REFERENCE NOTES}

1. Smith, J. C., \& Morris, D. D. A demonstration of conditioned aversion to saccharin solution using $X$-rays produced by a $3 \mathrm{Mev}$ Van de Graaf electron accelerator. Bulletin No. 15, 1964, Tallahassee: Florida State University, Institute for Molecular Biophysics, 1964.

2. Ternes, J. W., \& Smith, J. C. Circadian sensitivity to gamma rays as measured by conditioned saccharin aversion in rats. Paper presented at the meeting of the Psychonomic Society, St. Louis, October 1968. These data are available on a limited basis from the first author. The data are also discussed in an unpublished doctoral dissertation, Circadian cyclic sensitivity to gamma radiation as an unconditioned stimulus in sittvity to gamma radiationed taste aversion studies. Order No. 70-8579, University Microfilms, 300 N. Zeeb Rd., Ann Arbor, Michigan.

\section{REFERENCES}

Ahlers, R. H., \& Best, P. J. Novelty vs temporal contiguity in learned taste aversions. Psychonomic Sctence, 1971, 25, 34-36.

BARKER, L. M. CS duration, amount and concentration effects in conditioning taste aversions. Learning and Motivation, 1976, 7, 265-273.

BARKER, L., \& SMITH, J. C. A comparison of taste aversions induced by radiation and lithium chloride in CS-US and US-CS paradigms. Journal of Comparative and Physiological Psychology, 1974, 87, 644-655.

Barker, L., SUAREz, E., \& Gray, D. Backward conditioning of taste aversion in rats using cyclophosphamide as the US. Physiological Psychology, 1974, 2, 117-119.

Berman, R. F., \& Cannon, D. S. The effect of prior ethanol experience on ethanol induced saccharin aversion. Physiology and Behavior, 1974, 12, 1041-1044.

BEST, M. R. Conditioned and latent inhibition in taste-aversion learning: Clarifying the role of learned safety. Journal of Experimental Psychology, 1975, 104, 97-113.

Bond, N., \& DiGiusto, E. Amount of solution drunk as a factor in the establishment of taste aversion. Animal Learning and Behavior, 1975, 3, 81-84.

Bond, N., \& HARLAND, W. The effect of amount of solution drunk on taste-aversion learning. Bulletin of the Psychonomic Society, 1975, 5, 119-120.

Brooxshire, K. H., \& BrackaILl, R. M. Habituation to illness: Effects on acquisition and retention of a conditioned taste aversion. Psychonomic Science, 1972, 79, 385.

Carroll, M., Dinc, H., Levy, C., \& Smith, J. C. Demonstrations of neophobia and enhanced neophobia in the albino rat. Journal of Comparative and Physiological Psychology, 1975, 89, 457-467.

Domian, M. CS proexposure in taste aversion learning: Effects of deprivation and preexposure duration. Learning and Motivation. 1972, 3, 389-402.

Elkins, R. L. Attenuation of drug induced bait shyness to a palatable solution as an increasing function of its availability prior to conditioning. Behavioral Biology, 1973, 9, 221-226. (a)

ElkINs, R. L. Individual differences in bait shyness: Effects of drug dose and measurement technique. Psychological Record, 1973, 23, 349-358. (b)

Elkins, R. L. Bait shyness, acquisition and resistance to extinction as function of US exposure prior to conditioning. Physiological Psychology, 1974, 2, 34-343.

Etscors, F., \& Miller, R. Variations in the strength of conditioned taste aversion in rats as a function of time of inducement. Physiological Psychology, 1975, 3, 270-272.

Feign, R. D., San Joaquin, V. A., Haymond, M. W., \& WYATT, R. G. Daily periodicity of susceptibility of mice to to pneumonococcal infection. Nature, 1969, 224, 379-380.

Garcia, J., Ervin, F., \& Koelling, R. Bait shyness: A test for toxicity with $\mathrm{N}=2$. Psychonomic Science, 1967, 7, 245-246.

Garcia, J., Kimel.dorf, D. F, \& Koelling, R. A. Conditioned aversion to saccharine resulting from exposure to gamma radiation. Science, $1955,122,157-158$.

haus, E. F., Halberc, F., Locken, M. D., \& Kim, Y. S. Circadian rhymometry of mammalian radiosensitivity. In $\mathrm{C}$. Tobias \& P. Todd (Eds.) Space Radiation Biology. New York: Academic Press, 1974.

Kalat, J. W., \& Rozin, P. "Learned safety" as a mechanism in long-delay taste aversion learning in rats. Journal of Comparative and Physiological Psychology, 1973, 83, 198-201.

KEPPEL, G. Design and anabysis: $A$ researcher's handbook. Englewood Cliffs, N.J: Prentice Hall, Inc., 1973.

NaCHMAN, M., \& Ashe, J. H. Learned taste aversions in rats as a function of dosage, concentration, and route of administration of $\mathrm{LiCl}$. Physiology and Behavior, 1973, 10. 73-78. 
Nachman, M., \& Jones, D. R. Learned taste aversions over long delays in rats: The role of learned safety. Journal of Comparative and Physiological Psychology, 1974, 86, 949-956.

Pizzarello, D. J., Isaak, D., \& Chua, K. E. Circadian rhythmicity in the sensitivity of two strains of mice to whole-body radiation. Science, 1963, 145, 286-291.

RusAK, B., \& ZuCKER, I. Fluid intake of rats in constant light and during feeding restricted to the light or dark portion of the illumination cycle. Physiology and Behavior, 1974, 13, 91-100.

Revusky, S. H., \& Bedarf, E. W. Association of illness with prior ingestion of novel foods. Science, 1967, 155, 219-220.

SCHEVING, L. Daily circadian rhythm in rats to d-amphetamine sulfate: The effect of blinding and continuous illumination on the thythm. Nature, 1968, 219, 621-622.

Scheving, L. E., Ledral, D. F., \& Pauly, J. E. A circadian susceptibility rhythm in rats to phenobarbital sodium. Anatomical Record, 1968, 160, 741-750.
Siegel, P. S. Food intake in the rat in relation to the darklight cycle. Journal of Comparative and Physiological Psychology, 1961, 54, 294-301.

Siegel, P. S., \& Stuckey, H. L. The diurnal course of water and food intake in the normal mature rat. Journal of Comparative and Physiological Psychology, 1947, 40, 365-370.

Smith, J. C., \& BirkLE, R. A. Conditioned aversion to sucrose in rats using X-rays as the unconditioned stimulus. Psychonomic Science, 1966, 5, 271-272.

Ternes, J. W. Circadian cyclic sensitivity to gamma radiation in taste aversion conditioning. In L. E. Scheving, F. Halberg, \& J. E. Pauly (Eds.), Chronobiology, Tokyo: Igaku Shoin, 1974.

Vogel, J. R., \& Clody, D. E. Habituation and conditioned food aversion. Psychonomic Science, 1972, 28, 275-276.

(Received for publication February 11, 1976; revision accepted April 19, 1976.) 